\title{
Hair follicle growth by stromal vascular fraction- enhanced adipose transplantation in baldness
}

This article was published in the following Dove Press journal:

Stem Cells and Cloning:Advances and Applications

6 July 2017

Number of times this article has been viewed

\section{David Perez-Meza' \\ Craig Ziering ${ }^{2}$ \\ Marcos Sforza ${ }^{3}$ \\ Ganesh Krishnan ${ }^{4}$ \\ Edward Ball ${ }^{5}$ \\ Eric Daniels ${ }^{6}$}

'Ziering Medical, Marbella, Spain; ${ }^{2}$ Ziering Medical, Los Angeles, CA, USA; ${ }^{3}$ The Hospital Group, Bromsgrove, Worcestershire, ${ }^{4}$ Ziering Medical, Birmingham, ${ }^{5}$ Ziering Medical, London, UK; ' ${ }^{6}$ Kerastem Technologies, San Diego, CA, USA

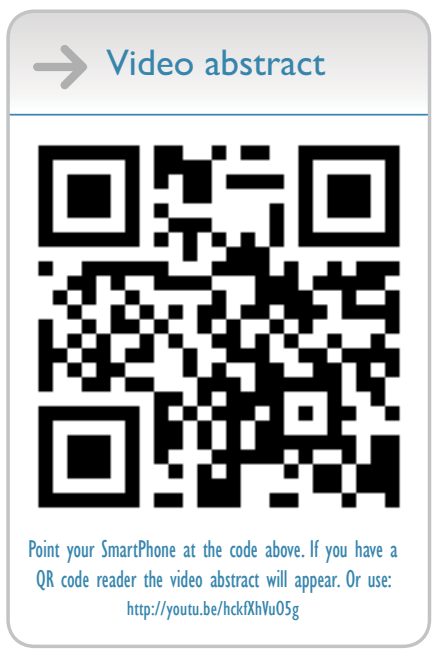

Correspondence: David Perez-Meza Perez-Meza Hair Institute, C/Strachan I, lero, Malaga 29015, Spain

Tel +34 672725959

Email drdavid@perez-meza.com
Abstract: Great interest remains in finding new and emerging therapies for the treatment of male and female pattern hair loss. The autologous fat grafting technique is $>100$ years old, with a recent and dramatic increase in clinical experience over the past 10-15 years. Recently, in 2001, Zuk et al published the presence of adipose-derived stem cells, and abundant research has shown that adipose is a complex, biological active, and important tissue. Festa et al, in 2011, reported that adipocyte lineage cells support the stem cell niche and help drive the complex hair growth cycle. Adipose-derived regenerative cells (also known as stromal vascular fraction [SVF]) is a heterogeneous group of noncultured cells that can be reliably extracted from adipose by using automated systems, and these cells work largely by paracrine mechanisms to support adipocyte viability. While, today, autologous fat is transplanted primarily for esthetic and reconstructive volume, surgeons have previously reported positive skin and hair changes posttransplantation. This follicular regenerative approach is intriguing and raises the possibility that one can drive or restore the hair cycle in male and female pattern baldness by stimulating the niche with autologous fat enriched with SVF. In this first of a kind patient series, the authors report on the safety, tolerability, and quantitative, as well as photographic changes, in a group of patients with early genetic alopecia treated with subcutaneous scalp injection of enriched adipose tissue. The findings suggest that scalp stem cell-enriched fat grafting may represent a promising alternative approach to treating baldness in men and women.

Keywords: stem cell, alopecia, adipose, stromal vascular fraction, transplantation

\section{Introduction}

Male and female pattern of hair loss (MPHL and FPHL) is characterized by progressive thinning of the scalp hair. MPHL affects half or more of males before the age of 50 years. ${ }^{1-6}$ In women, FPHL is a common condition characterized by diffuse thinning and reduction of hair density in the frontal and mid-scalp and crown with retention of the hairline. Prevalence of FPHL increases with age, and $\sim 50 \%$ of women experience FPHL by age $50 .^{7-9}$ Great interest remains in finding new and emerging therapies for the treatment of MPHL and FPHL. Treatment options for men and women with hair loss include medical therapy, hair transplant surgery, low-level laser therapy, hair systems, micropigmentation of the scalp, and topical concealer fibers. ${ }^{10-17}$ These options are not without shortcomings, and thus researchers are always looking for new and alternative therapies. ${ }^{18-23}$ One emerging area of clinical and scientific focus lies in exploring the role of adipose tissue (fat), and specifically autologous adipose transplantation, in the complex, hair growth cycle. While modern efforts to seek a treatment for pattern baldness have been ongoing for decades, autologous fat grafting is a technique practiced

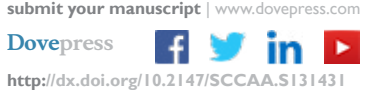

Stem Cells and Cloning:Advances and Applications 2017:10 1-10

(c) (7) (5) 2017 Perez-Meza et al. This work is published and licensed by Dove Medical Press Limited. The full terms of this license are available at https://www.dovepress.com/terms.

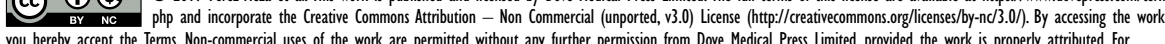
permission for commercial use of this work, please see paragraphs 4.2 and 5 of our Terms (https://www.dovepress.com/terms.php). 
for over a century. The procedure has enjoyed a recent and dramatic increase in clinical experience over the past 10-15 years, and this resurgence in clinical activity has been, in part, driven by the findings of Zuk et al, reporting the presence of adipose-derived stem cells (ADSCs). ${ }^{24}$ Subsequently, abundant research has supported the fact that adipose is a biologically active, a complex, and an important tissue. In the context of the scalp, Festa et al reported that adipocyte lineage cells support the stem cell niche and help drive the hair growth cycle, while Shin et al documented the role of ADSC-conditioned media in promoting hair growth in female pattern alopecia. ${ }^{25,26}$

Today, autologous fat is transplanted primarily for an esthetic and reconstructive volume effect and, traditionally, rates of graft retention have been widely varied and a number of strategies have been applied to increase this rate of graft take. ${ }^{27}$ One such strategy is to enrich the adipose with stromal vascular fraction (SVF), a heterogeneous group of generally well-characterized multinucleated cells that can be reliably extracted from adipose by using automated systems. These cells work largely by paracrine mechanisms to support adipocyte viability. ${ }^{27}$ Beyond volumization, many surgeons have reported positive skin and hair changes posttransplantation. ${ }^{28,29}$ This background spurred these authors to ask if one could drive or restore the hair cycle by transplanting adipose enriched with SVF to the scalp in patients with MPHL and FPHL. In this pilot case series, the authors' first experience and findings are reported.

\section{Materials and methods Subjects}

Patients in this clinical series were healthy men and woman aged 18-55 years with MPHL and FPHL graded as NorwoodHamilton grades II-VI or Ludwig Class I-III. 2,9 Over a period of 3 months from March through May 2014, a total of nine subjects ( 8 men and 1 woman) presented to a private hospital (Dolan Park Hospital, Bromsgrove, UK) affiliated specialty clinic exclusively focused on the diagnosis and treatment of hair loss. A thorough medical and hair history and physical examination was performed to diagnose male and/or female pattern alopecia. The investigators reviewed the inclusion and exclusion criteria (Table 1) to screen patients accordingly. Importantly, patients who reported the administration of any agent aimed at affecting hair growth within 6 months prior to

Table I Inclusion and exclusion criteria

\begin{tabular}{|c|c|}
\hline Inclusion & $\begin{array}{l}\text { - Diagnosis of MPHL or FPHL } \\
\text { - Age of I8-55 years } \\
\text { - Norwood-Hamilton grades II-VI or Ludwig Class I-III } \\
\text { - Provide written informed consent and comply with the study requirements } \\
\text { - No clinically significant disease or abnormal laboratory results at the time of screening visit } \\
\text { - Patient has adequate abdominal or other subcutaneous adipose tissue accessible by syringe-based lipoharvest } \\
\text { - For women of child-bearing potential: negative pregnancy test at screening visit } \\
\text { - Ability to safely undergo liposuction that will result in the harvest of a sufficient quantity of adipose tissue } \\
\text { - Subject is willing to maintain the same hair length and hair color during the study period } \\
\text { - Subject is willing to have a I-mm tattoo in the study area } \\
\text { - Ability to complete study procedures, patient surveys, and pictures }\end{array}$ \\
\hline Exclusion & $\begin{array}{l}\text { - Use of a prescription or over-the-counter hair growth agent } 6 \text { months prior to undergoing a procedure } \\
\text { - Treatment with an investigational product or procedure within } 30 \text { days or plans to participate in another clinical study } \\
\text { - Subject who has previously failed or has been deemed nonresponsive to a previous experimental hair loss treatment } \\
\text { - History of autoimmune disease or organ transplantation } \\
\text { - Diagnosis of cancer, receiving active treatment } \\
\text { - Active systemic infection } \\
\text { - Requires chronic antibiotic or steroidal therapy (and anticoagulants) } \\
\text { - Use of systemic agents that increase bleeding or clotting, or disorders associated with these effects } \\
\text { - Clinically significant medical or psychiatric illness currently or within } 30 \text { days of study screening as determined by the } \\
\text { investigator } \\
\text { - Prior surgery in the treatment area } \\
\text { - Any disease or condition (medical or surgical) that, in the opinion of the investigator, might compromise hematologic, } \\
\text { cardiovascular, pulmonary, renal, gastrointestinal, hepatic, or central nervous system function; or any condition that would } \\
\text { - Place the subject at increased risk } \\
\text { - Kregnant or lactating women or women trying to become pregnant } \\
\text { - Subject has any disorder that may prevent compliance } \\
\text { - Subject who is part of the study staff, a family member, or a friend } \\
\text { - Diabetes } \\
\text { - Subject who has a sensitive, irritated, or abraded scalp area }\end{array}$ \\
\hline
\end{tabular}

Abbreviations: FPHL, female pattern of hair loss; MPHL, male pattern of hair loss. 
presentation, regardless of whether they were prescribed by a physician or obtained over the counter, were excluded from participation. Written informed consent for the procedure, including photographing and publication in a medical and scientific journal for educational purposes, was obtained from all subjects, and the protocol was reviewed and approved by the hospital's Internal Medical Advisory Committee (Dolan Park MAC). In addition, the Declaration of Helsinki and Belmont Report were followed in the study.

\section{Measurements}

Patients electing to enroll in the case series were documented by using both macrophotography and global photography. Macrophotography was obtained and the results were evaluated by using the Fotofinder System TrichoScale software (Fotofinder, Columbia, MD, USA). To obtain macrophotographs, a $1 \mathrm{~cm}^{2}$ region of scalp in the affected area was shaved down to $1 \mathrm{~mm}$ in length. Hairs in this region of scalp were first dyed, and photos were captured by using an adapter connected to a smartphone. Images were then uploaded to a portal and could then be analyzed by using TrichoScale software. For each microphotographic data point, the patients were asked to report to the clinic at time 0 and 48 hours as the authors initially wanted to capture an anagen/telogen ratio. However, as patients found this schedule difficult to comply with, the authors eliminated this measurement and data obtained were hair counts, anagen/telogen percentages, and cumulative thickness. In an effort to ensure that measurements were taken in the same location over a series of time points, a small micro-tattoo was applied by using a $20 \mathrm{G}$ needle and semi-permanent black-ink. For global photographs, the FotofinderMediscope Selective System was installed within the clinic. This system allows a fixed-depth image capture that is then uploaded and managed with the Fotofinder software. Several images were taken, when available, at preoperative baseline, 6 weeks, 12 weeks, and 24 weeks. For one patient, 32-week global photographic images were captured. Table 2 summarizes the schedule of visits and procedures.

\section{Procedure}

\section{Liposuction surgical technique}

On the day of surgery, specific surgical goals were reviewed with patients regarding lipoaspiration and scalp injection of adipose enriched with adipose-derived regenerative cells (ADRCs - also known as SVF) to address their genetic alopecia. All patients had a body mass index (BMI) within normal limits. All patients were considered generally healthy, and no patients had comorbidities such as diabetes or high blood pressure. Under either general anesthesia or twilight anesthesia, tumescent fluid $(500 \mathrm{~mL}$ of Ringer's lactate [RL] with $20 \mathrm{~mL}$ of $1 \%$ lidocaine [Aspen Trading, Dublin, Ireland] and $20 \mathrm{~mL}$ of bupivacaine $0.5 \%$ and $1 \mathrm{mg}$ of epinephrine) was infiltrated and fat tissue was harvested with a $60 \mathrm{~mL}$ Luer Lock syringe (Becton Dickinson, Franklin Lakes, NJ, USA) from the abdominal and flank areas (Figure 1) by using a 2.4 mm cannula (Sforza Harvester; Tulip Medical Products, San Diego, CA, USA). An average volume of $122 \mathrm{~mL}$ of adipose was harvested from patients. The lipoaspirate was divided into two aliquots. The first aliquot was processed utilizing the Puregraft system (Puregraft LLC, Solana Beach, CA, USA) to obtain a purified autologous fat graft (Figure 2). The second aliquot was processed by using the KerastemCelution System (Kerastem LLC, Solana Beach, CA, USA) to obtain a 5.0-mL cell suspension of ADRCs (Figure 3 ). The processing of ADRCs took 75-90 minutes and varied depending upon the amount of tissue to be processed.

\section{Scalp injection}

While still under general or twilight anesthesia, patients were administered an anesthetic ring block with $1 \%$ lidocaine (1:200,000 epinephrine) solution to the affected area of scalp to allow for adequate and sufficient local anesthesia. After

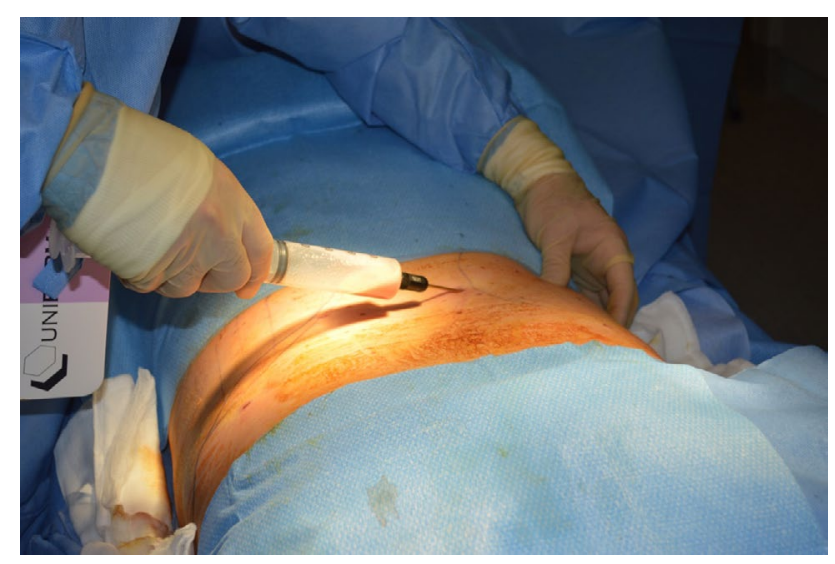

Figure I Small volume liposuction.

Table 2 Schedule of visits and procedures

\begin{tabular}{lllll}
\hline Screen/evaluation & $\begin{array}{l}\text { Baseline macro- and } \\
\text { global photography } \\
\text { (day -2 and day 0) }\end{array}$ & $\begin{array}{l}\text { Procedure } \\
\text { (day 0) }\end{array}$ & $\begin{array}{l}\text { 6-Week macro- and } \\
\text { global photography }\end{array}$ & $\begin{array}{l}\text { I2-Week macro- and } \\
\text { global photography }\end{array}$ \\
\hline
\end{tabular}




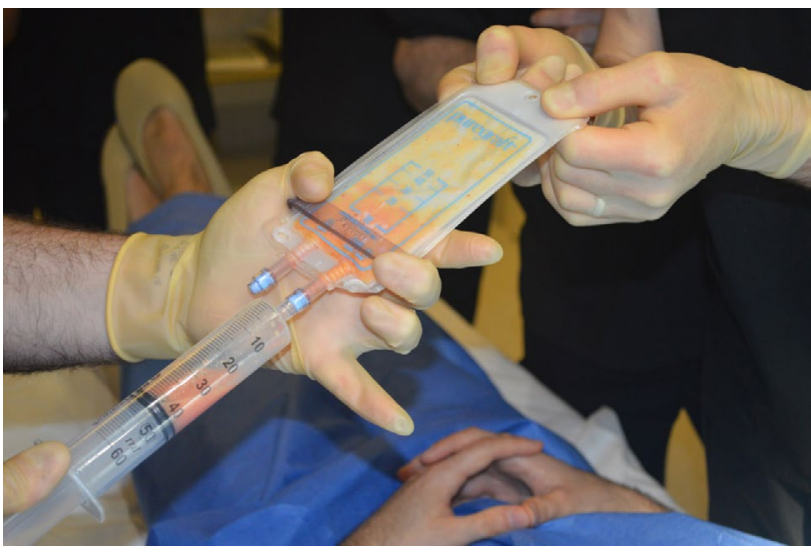

Figure 2 Puregraft fat purification system.

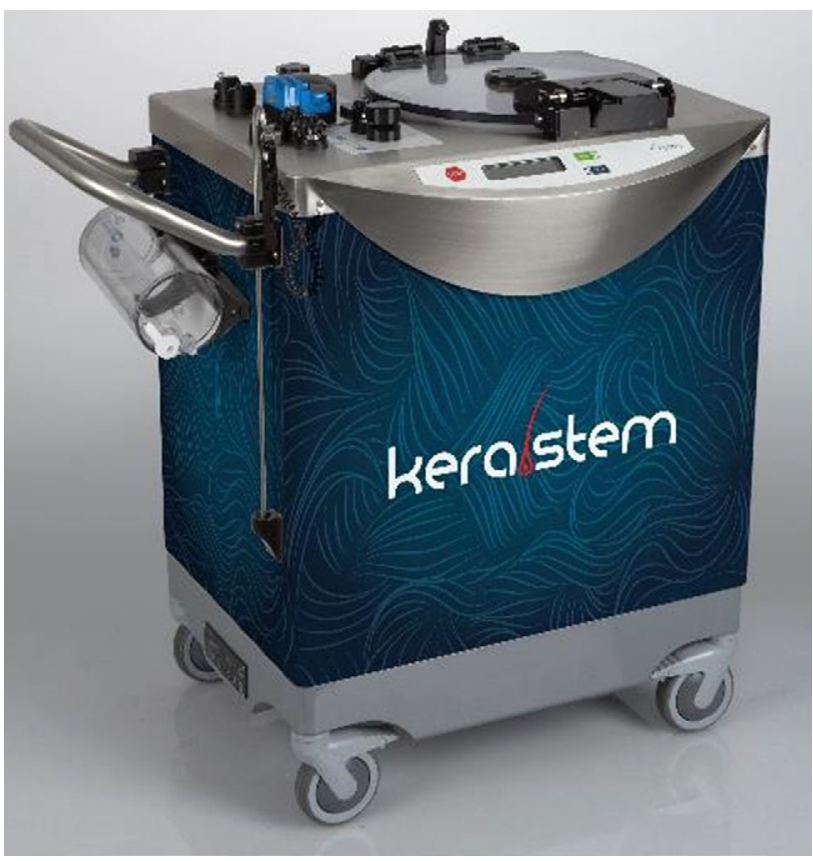

Figure 3 Kerastem Celution system (courtesy of Kerastem, LLC).

awakening from general anesthesia, patients were moved to a standard clinic procedure room and the affected areas of scalp were marked. The amount of volume injected into the scalp was determined, per protocol, to be $1.0 \mathrm{~mL} / \mathrm{cm}^{2}$ scalp. The composition of this $1.0 \mathrm{~mL}$ was a mixture of purified adipose from Puregraft, ADRCs from Kerastem Celution, and Lactated Ringer's (LR). The mixing and preparation of enriched adipose occurred in a sterile environment within the procedure room. After the preparation of the tissue was complete, needle-puncture incisions were made near the area to be treated. The surgeon injected the fat in a fanlike patterned movement in the subcutaneous tissue of the scalp with a $1.0-\mathrm{mL} \mathrm{cc}$ Luer Lock syringe attached to a $1.2-\mathrm{mm}$ cannula (Tulip Injector; Tulip Medical Products, San Diego, CA, USA), aiming to apply $1.0 \mathrm{~mL}$ of enriched fat per square

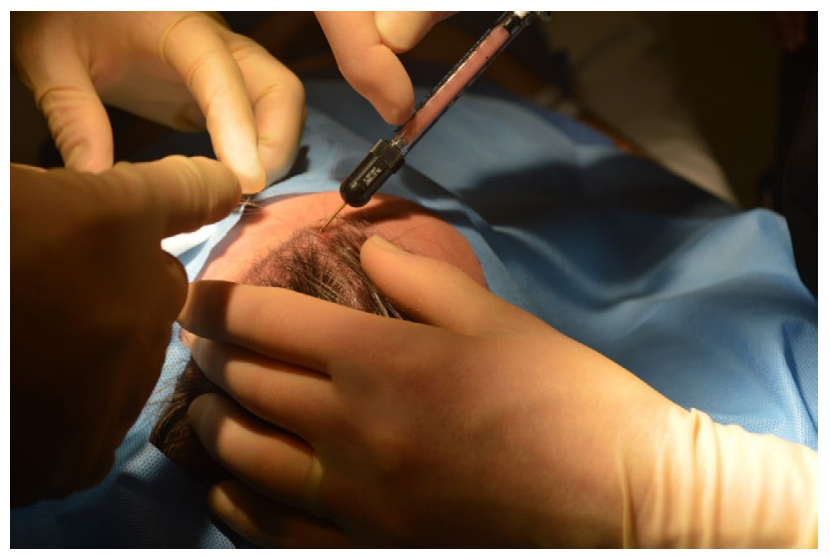

Figure 4 Scalp area prepared for injection.

Table 3 Summary of patient demographics, including the amount of adipose harvested and injected

\begin{tabular}{ll}
\hline Average age of patients (range) & $29(19-54)$ years \\
Grade(s) of hair loss & 3 \\
Average volume of adipose harvested & $122 \mathrm{~mL}$ \\
Average volume of adipose + cells injected & $30 \mathrm{~mL}$ \\
\hline
\end{tabular}

centimeter of scalp (Figure 4). Table 3 summarizes patient demographics, including the amount of adipose harvested, processed, and injected.

It should be noted that all patients had a single dose of $1 \mathrm{~g}$ of cefuroxime as a prophylactic antibiotic 1 hour before the surgery started. All patients had compression socks (Preventx, Loughborough, UK) and a prophylactic pneumatic deep-vein thrombosis (DVT) system (Flowtron; Huntleigh Healthcare, Eatontown, NJ, USA) during the procedure. Patients were discharged with compression garments on the area of fat tissue harvest. All patients remained in the procedure room 1 hour postscalp injection to observe for any complications. No bandages were applied to the scalp for discharge.

\section{Statistical analysis}

Hair counts, anagen percentage, telogen percentage, and cumulative thickness were obtained by using the methods described above. To form a more reliable baseline measure, for those measures where a time 0 and 48 hours was available, the values were averaged. The improved reliability from averaging was tested by obtaining a Cronbach coefficient alpha, and its value supported averaging. Differences between baseline (time 0 and 48 hours or time 0 alone) were calculated at various time points for each subject. Mean differences were then tested by paired $t$-tests. It should be noted that the sample size decreases over time, so less weight should be given to observed differences at low-N time points. The distribution of the data is approximately normal, justifying the use of 
parametric testing. However, as more data are collected, this assumption will be assessed and the necessary statistical test used accordingly will be modified. $P$-values of $<0.05$ were considered to indicate statistical significance.

\section{Results}

A total of nine patients underwent the procedure described above. One patient did not return to the clinic for any followup after surgery, and therefore, data on that patient were not included. One patient was lost to follow-up after 6 weeks and another patient was lost to follow-up after 3 months. Therefore, 6-month follow-up data are available for six patients. One patient had follow-up measurements 8 months postoperatively. Table 4 summarizes the number of subjects and the associated timeline for all comers.

In one particularly lean subject, an inadequate amount of lipoaspirate was harvested to successfully operate the SVF harvesting devices, and therefore, the decision was made to inject fat alone (fat not enriched with SVF). In addition, in one subject, half of the affected area of the scalp was treated with cell-enriched adipose, while the other half was treated only with saline injection.

One subject suffered hematoma in the region of the hairline during the injection of enriched adipose. This was self-limiting, and the patient did not require any intervention except for additional observation prior to discharge from the facility.

Table 5 summarizes the quantitative measures of all areas of scalp that had some tissue treatment (fat + SVF as well as

Table 4 Number of subjects available for analysis and associated timelines relative to baseline

\begin{tabular}{ll}
\hline Time point & Number of subjects \\
\hline 6 weeks & 8 \\
12 weeks & 7 \\
24 weeks & 6 \\
32 weeks & 1 \\
\hline
\end{tabular}

Table 5 24-week change in mean TrichoScale values (relative to baseline mean) for patients treated with fat + SVF and fat alone

\begin{tabular}{llllll}
\hline $\mathbf{N}$ & Variable & $\begin{array}{l}\text { 24-week } \\
\text { change } \\
\text { in mean }\end{array}$ & SD & P-value & $\begin{array}{l}\text { \% change } \\
\text { of mean }\end{array}$ \\
\hline 6 & $\begin{array}{l}\text { Hair count (number } \\
\text { of hairs } / \mathrm{cm}^{2} \text { scalp) }\end{array}$ & 28.4 & 17.3 & 0.010 & 20.5 \\
6 & Anagen \% & 24.1 & 28.5 & 0.094 & 82.5 \\
6 & Telogen \% & -24.1 & 28.5 & 0.094 & -38.4 \\
6 & Cumulative thickness & 1.04 & 1.43 & 0.133 & 18.3 \\
\hline
\end{tabular}

Notes: $\mathrm{N}$ represents only the number of subjects, with each patient having multiple underlying measurements for each time point, and the percent change of mean represents the averaged percentage increase/decrease of individual means.

Abbreviations: SVF, stromal vascular fraction; SD, standard deviation.
Table 6 24-week change in mean TrichoScale values (relative to baseline mean) for patients treated with fat + SVF

\begin{tabular}{llllll}
\hline $\mathbf{N}$ & Variable & $\begin{array}{l}\text { 24-week } \\
\text { change } \\
\text { in mean }\end{array}$ & SD & P-value & $\begin{array}{l}\text { \% change } \\
\text { of mean }\end{array}$ \\
\hline 5 & $\begin{array}{l}\text { Hair count (number } \\
\text { of hairs } / \mathrm{cm}^{2} \text { scalp) }\end{array}$ & 31.2 & 17.7 & 0.017 & 23.2 \\
5 & Anagen \% & $25.2 \%$ & 31.1 & 0.150 & 93.4 \\
5 & Telogen \% & $-25.2 \%$ & 31.1 & 0.150 & -35.6 \\
5 & Cumulative thickness & 1.48 & 1.05 & 0.034 & 24.2 \\
\hline
\end{tabular}

Notes: $\mathrm{N}$ represents only the number of subjects, with each patient having multiple underlying measurements for each time point, and the percent change of mean represents the averaged percentage increase/decrease of individual mean. Abbreviations: SVF, stromal vascular fraction; SD, standard deviation.

Table 7 24-week change in mean TrichoScale values (relative to baseline mean) for single patient treated with fat alone

\begin{tabular}{llll}
\hline $\mathbf{N}$ & Variable & $\begin{array}{l}\text { 24-week change } \\
\text { in mean }\end{array}$ & $\begin{array}{l}\text { \% change } \\
\text { of mean }\end{array}$ \\
\hline $\mathrm{I}$ & Hair count & 14 & 7.5 \\
$\mathrm{I}$ & Anagen \% & 18.3 & 28.2 \\
$\mathrm{I}$ & Telogen \% & -18.3 & -52.3 \\
$\mathrm{I}$ & Cumulative thickness & -1.15 & $-11 . \mathrm{I}$ \\
\hline
\end{tabular}

Notes: $\mathrm{N}$ represents only the number of subjects, with each patient having multiple underlying measurements for each time point, and the percent change of mean represents the averaged percentage increase/decrease of individual mean.

fat alone - does not include area of scalp treated with saline) at 6 months.

The quantitative measures of the one subject who received fat alone were analyzed separately at 6 months and are summarized in Table 6 . The quantitative 6-month outcomes, relative to baseline, of the patient who underwent fat-alone treatment are summarized in Table 7. A number of other global and macrophotographs are depicted in Figures 5-10.The 6-month quantitative measurements of the one patient who served as his own control, relative to baseline, are summarized in Table 8 . The global and macrophotographs for this patient at 24 weeks are shown in Figures 11-13.

\section{Discussion}

The degree of hair loss in male patients is generally classified by using the Norwood Hamilton Classification, and FPHL is evaluated based on the Savin scale. ${ }^{7-9}$ The incidence and prevalence of the condition are generally well documented in both the genders. Stough et al reported that in White males, $30 \%$ have androgenic alopecia by age 30 years and $50 \%$ by age 50 years with lower incidences seen in African-American, Chinese, and Japanese populations. ${ }^{5}$ In a population-based report looking at MPHL, the authors reported that in the 


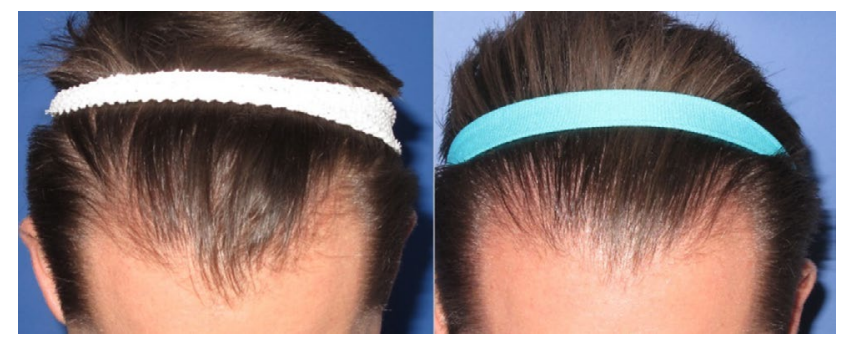

Figure 5 Baseline (left) versus 24-week (right) global photograph of treated (fat + stromal vascular fraction) hairline.

30- to 35-year age group, grade I hair loss was in 51\%, grade II was in $43 \%$, and grade VI was in only $\sim 19 \%$, clearly highlighting early hair loss in the younger population. ${ }^{6} \mathrm{Of}$ the 1,005 men in the study aged from 30 to 50 years, $44 \%$ were found to have grades I-III hair loss.

In women, diffuse thinning and loss of hair density with maintenance of the frontal hairline describe the typical pattern of loss. ${ }^{5}$ In one report, the prevalence of early, clinically detectable FPHL was in $12 \%$ of females between 20 and 29 years of age and in $25 \%$ by 49 years of age. ${ }^{2}$ Gan and Sinclair documented the distribution of hair loss in 752 women by using a modified 5-point grading scale. ${ }^{10}$ Below the age of 40 years, $99 \%$ of women reporting loss documented early-stage loss. In summary, a significant percentage of both the male and female population suffers from androgenic alopecia at a relatively early age.

The current treatment regimen for androgenetic alopecia is a spectrum ranging from noninvasive medical approaches to follicular unit transplantation, including the donor strip and punch (follicular unit extraction) donor harvesting techniques and robot-assisted technique, where thousands of follicular units are transplanted..$^{10-17}$ On the medical treatment side, the two medications currently approved for treatment of genetic pattern alopecia by the US Food and Drug Administration (FDA) are finasteride (for men only) and minoxidil. ${ }^{12,13}$ Both of these medicines carry potential untoward side effects. For finasteride, sexual dysfunction, particularly for the younger patients who are most likely to present with early hair loss, was seen in between $2.1 \%$ and $3.8 \%$ of men. ${ }^{21}$ It remains important to determine the causes of hair loss (diet, crash diets, anemia, stress, hormonal imbalances, post-cancer treatments, medications, trauma, burns, etc) in men and women before providing the appropriate treatment.

The initial treatment of early MPHL and FPHL alopecia is typically noninvasive, and the two medications approved by the FDA today are minoxidil $2 \%$ and $5 \%$ foam and finasteride $1 \mathrm{mg}$. For minoxidil, it is reported that approximately one-third of patients with MPHL and FPHL respond with regrowth. ${ }^{23}$ Low-level laser therapy may also represent an FDA-approved treatment option for baldness. ${ }^{11,15}$ Today, a surgical hair transplant option remains the gold standard for the treatment of genetic alopecia. However, hair transplant is generally not offered to patients with early MPHL and FPHL, patients with diffuse thinning, poor donor availability, and scarring alopecias (lichen planus pilaris, lupus, frontal fibrosis alopecia, and others). In addition, a percentage of patients do not wish to continue with medical therapies that may be necessary or recommended after surgical transplantation. Therefore, an important gap exists between these medicinal and transplant options, and hair follicle stimulation with
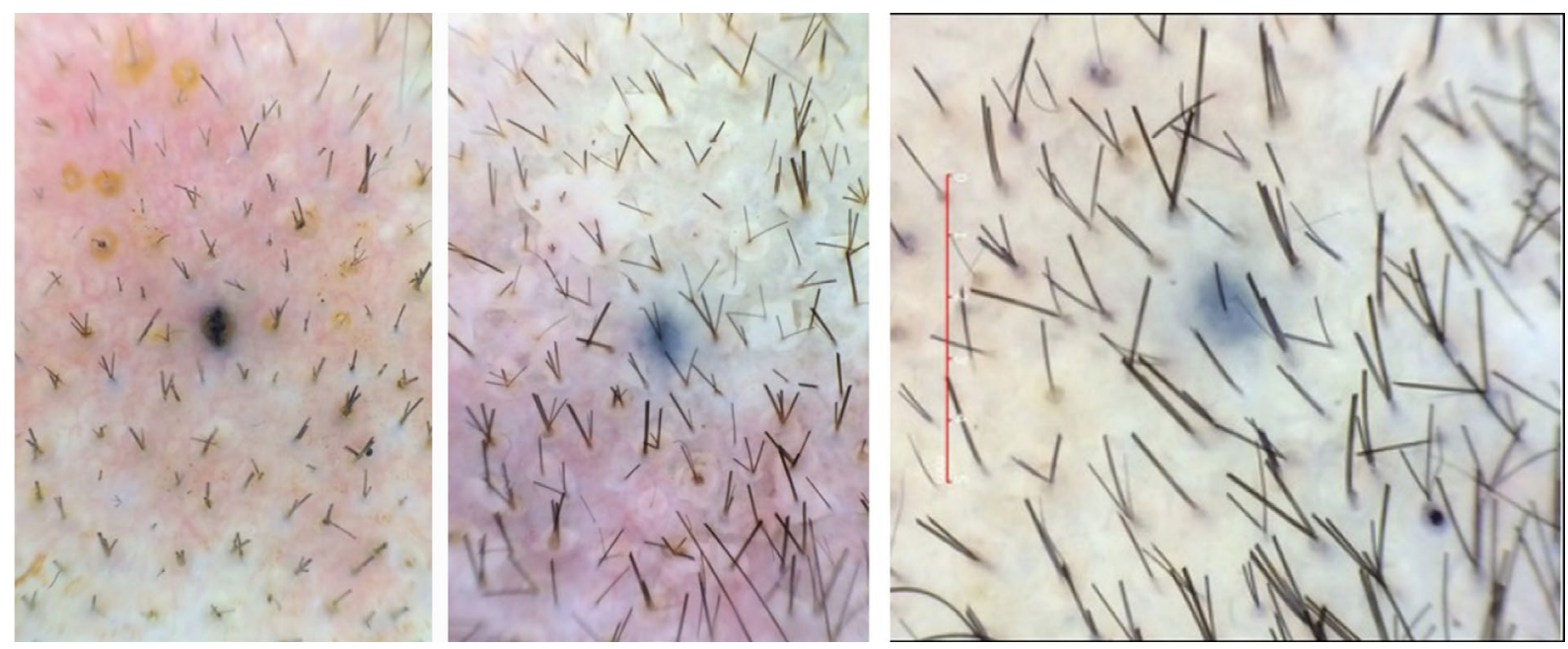

Figure 6 Baseline (left) versus 6-week (middle) versus 24-week (right) macrophotograph of the patient in Figure 5. Note: Magnification: $20 \times$. 


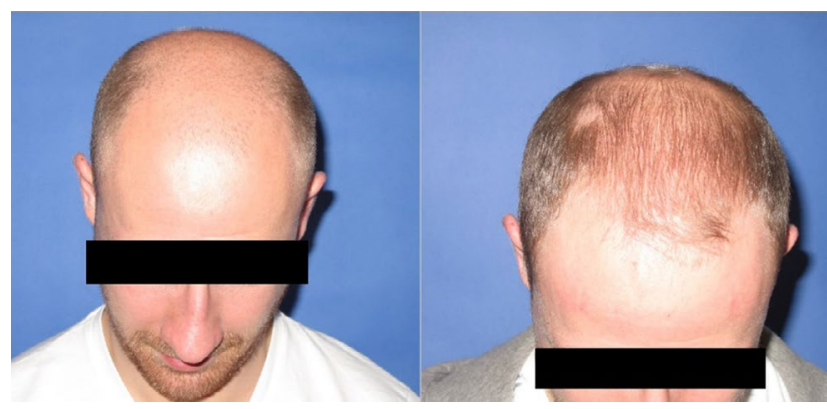

Figure 7 Baseline (left) versus (right) 24-week global photograph of treated (fat + stromal vascular fraction) midscalp.

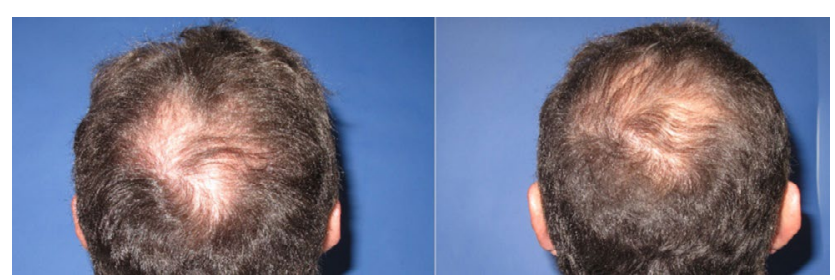

Figure 8 Baseline (left) versus 24-week (right) global photograph of treated (fat + stromal vascular fraction) vertex.
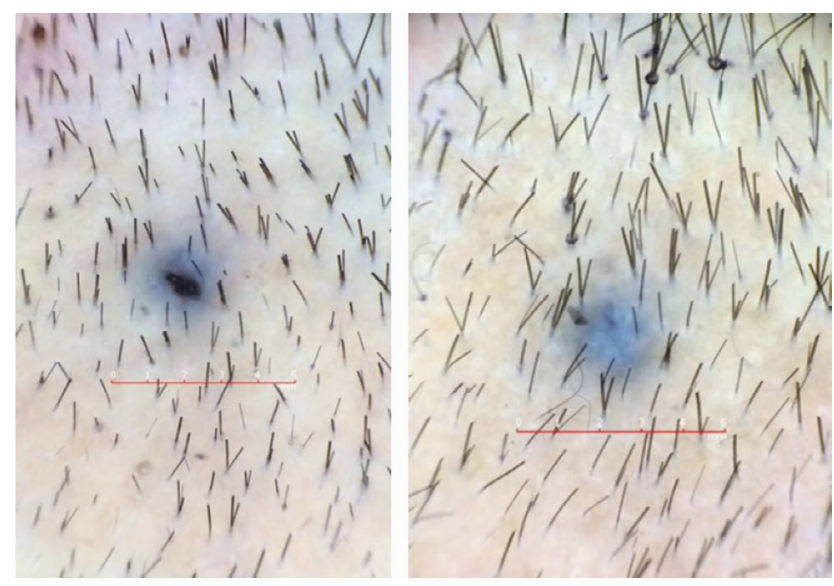

Figure 9 Baseline (left) versus 24-week (right) macrophotograph of the patient in Figure 8.
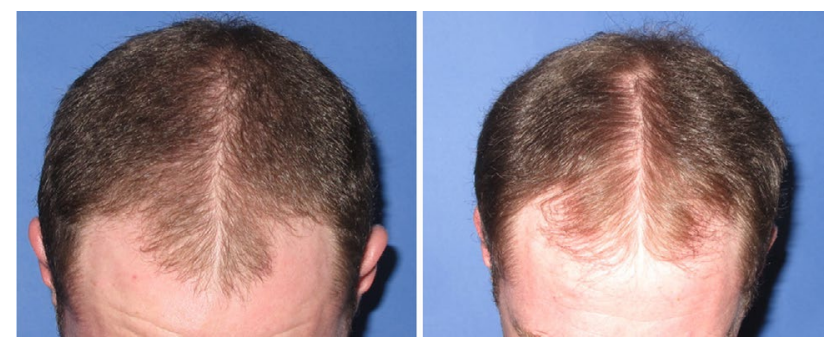

Figure 10 Baseline (left) versus 24-week (right) global photograph of treated (fat alone) hairline.
Table 8 24-week change in mean values for the single patient that received both fat + SVF on one region of their scalp versus a saline control to a sister region of the scalp

\begin{tabular}{llll}
\hline $\mathbf{N}$ & Variable & $\begin{array}{l}\text { 24-week fat }+ \\
\text { SVF change } \\
\text { in mean }\end{array}$ & $\begin{array}{l}\text { 24-week } \\
\text { control change } \\
\text { in mean }\end{array}$ \\
\hline I & $\begin{array}{l}\text { Hair count (number of } \\
\text { hairs } / \mathrm{cm}^{2} \text { scalp) }\end{array}$ & 44.1 & 1.33 \\
I & $\begin{array}{l}\text { Anagen \% } \\
\text { I }\end{array}$ & 48.6 & 29.48 \\
I & Celogen \% & -48.6 & -29.48 \\
\hline
\end{tabular}

Note: $\mathrm{N}$ represents only the number of subjects, with each patient having multiple underlying measurements for each time point.

Abbreviation: SVF, stromal vascular fraction.

enriched adipose, as a standalone or as an adjuvant therapy, may have a role.

In this pilot case series, a mean increase of 31 hairs $/ \mathrm{cm}^{2}$ of scalp (represents a $23 \%$ relative percentage increase) is documented in patients undergoing treatment of fat plus SVF. In comparison, the one subject who had fat alone documented a mean increase of 14 hairs $/ \mathrm{cm}^{2}$ of scalp, suggesting that while fat alone may represent an approach for early baldness, addition of SVF may enhance this response. For the one patient who served as his own control, there seemed to be a robust response to the area receiving treatment (mean increase of 44.1 hairs $/ \mathrm{cm}^{2}$ of scalp) relative to the area receiving placebo saline (mean change of 1.33 hairs $/ \mathrm{cm}^{2}$ ). Importantly, this clinical series documented material growth by macrophotography which was consistent with the global photographs taken for these patients. The authors feel that this concordance between macro- and global photographs is important in substantiating further development of this therapeutic approach.

During hair follicle growth (anagen phase) cycle, the hair follicle delves deep into the rich dermal macroenvironment as it matures where it is surrounded by large lipid-filled adipocytes. These intradermal adipocytes regenerate with faster kinetics than other adipose tissue depots, and such growth parallels with the hair cycle, suggesting an interplay exists between hair follicle cells and adipocyctes. ${ }^{30}$ Thus, it has been established that adipose is an integral part of the normal hair cycle, and it is hypothesized that telogen may be due to an absence of adipose tissue as it is reported that hair loss and decreased adipocytes occur together. ${ }^{30,31}$ Therefore, the transplantation of adipose tissue, or autologous fat transfer (AFT), into the subcutaneous layer of fat in the scalp for the purposes of stimulating hair growth is consistent with the 

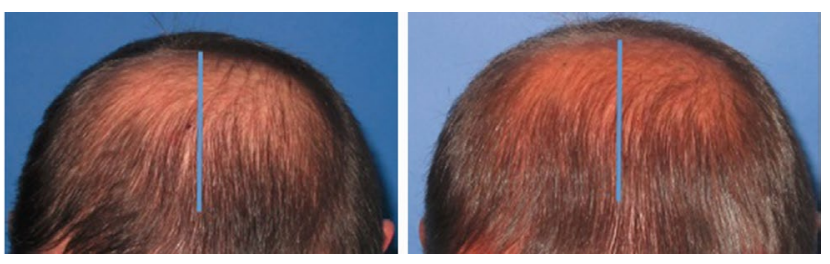

Figure II Baseline (left) versus 24-week (right) global photograph of treated vertex. Area on the left of midline treated with saline and area to the right of midline treated with fat + stromal vascular fraction.
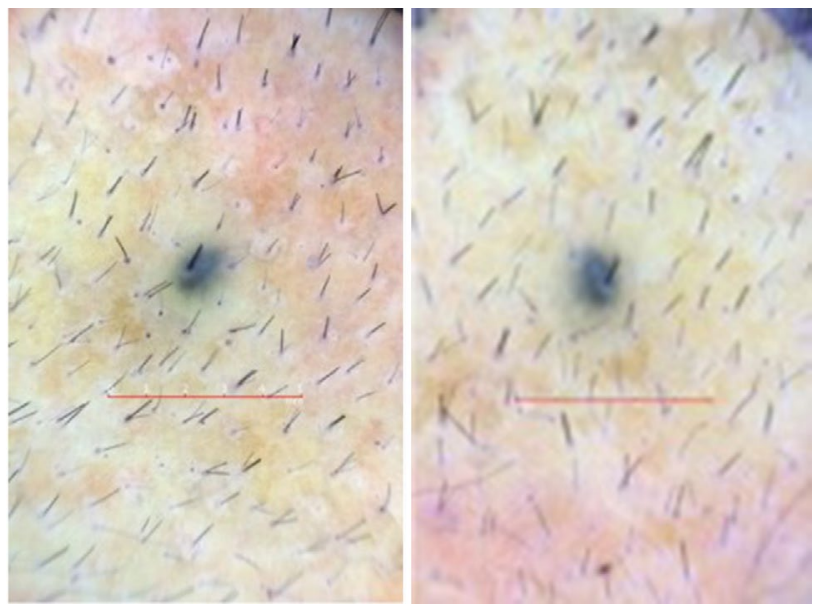

Figure 12 Baseline (left) versus 24-week (right) macrophotograph of saline treated vertex of the patient in Table 8.

Note: Magnification: $20 \times$

reported literature that indicates hair loss and adipose loss occur in tandem.

\section{Autologous fat transfer}

In an AFT procedure, a patient's subcutaneous adipose tissue is aspirated from one location (most commonly the abdomen or flanks) and transferred into another depot of subcutaneous fat located throughout the body (eg, mid-face). This procedure is reported to be practiced by physicians for over 100 years, and autologous fat should be free from problems often associated with artificial materials or from allergic reactions. ${ }^{32}$ However, AFT is not without its own limitations, most significant of which is the fact that an unpredictable amount of the transferred fat can die as a result of damage during tissue harvest, processing, and implantation, leading to loss of the quality and quantity of cells, tissue volume, and therefore a degree of unpredictability in outcome.

The process of fat transfer necessarily involves disconnecting the fat from its blood supply, implanting it into the defect, and then waiting for natural healing processes to incorporate the transferred tissue with native fat. Survival of the transferred tissue is dependent upon harvest and processing approaches that maximize tissue viability. ${ }^{33}$ It is also dependent upon simple diffusion to supply nutrients andoxygen

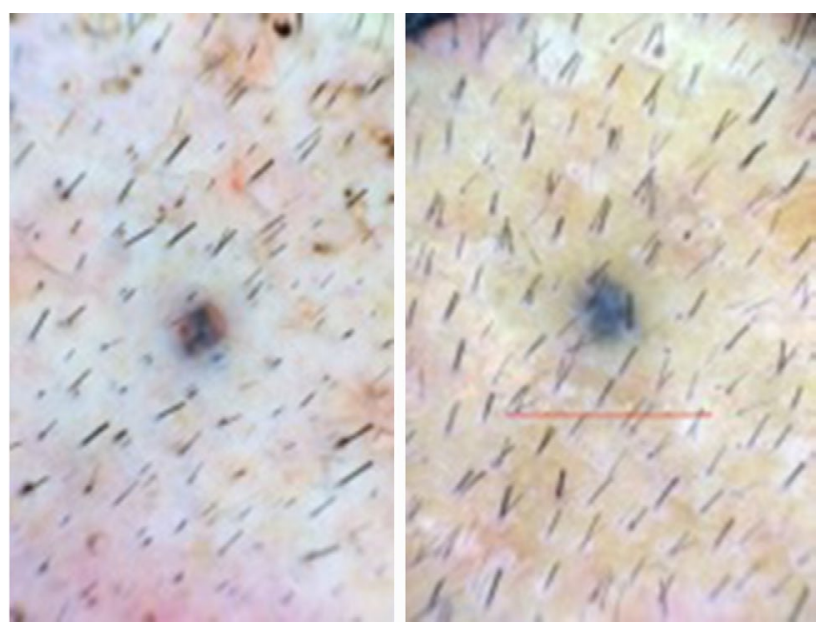

Figure I 3 Baseline (left) versus 24-week (right) macrophotograph of fat + stromal vascular fraction-treated vertex of the patient in Table 8. Note: Magnification: $20 \times$.

and to remove waste until such time as healing processes restore its blood supply. Diffusion through a solid tissue such as fat is only effective across a distance of a few millimeters. Consequently, any transferred tissue that is more than a few millimeters away from the blood supply of recipient site tissue is at risk of dying. Loss of graft tissue from this problem is a common issue, and clinicians frequently overcorrect adding extra tissue in an effort to compensate for inevitable tissue loss that has been estimated at between $20 \%$ and $80 \%$ of the implanted tissue. ${ }^{34-36}$ As a result of this unpredictability, defect repair frequently requires multiple repeated or staged procedures performed at intervals of $\geq 3$ months. For example, one large study reports up to five treatments needed (mean $=$ three treatments) in order to achieve success in restoring volume. ${ }^{37}$ This leads to delays in achievement of effective treatment of the defect, expense, and the higher morbidity of repeated tissue collection and implantation.

A number of investigators have evaluated ways by which the healing process and graft take can be modulated in an effort to understand and augment graft retention and, thereby, limit the number of procedures needed to achieve successful treatment. For example, animal studies have shown that use of agents that stimulate the healing process (eg, gene therapy with factors that stimulate new blood vessel growth) can increase the survival of transferred tissue and that, conversely, agents that inhibit healing reduce survival. ${ }^{38,39}$ Recent preclinical and clinical data have shown that, in addition to being a source of tissue for soft tissue filling, human adipose tissue contains cells that have the ability to promote healing. ${ }^{40,41} \mathrm{Zhu}$ et al have used an animal model to show that coating one volume of adipose tissue with cells isolated from another volume of adipose tissue results in an approximate doubling of graft retention at 6 and 9 
months. ${ }^{42}$ This finding has been confirmed by an independent study. ${ }^{43}$ The concept of this approach is that signals generated at the interface between implanted fat and adjacent breast fat will induce improved healing. Increasing the number of cells capable of generating these signals at this interface will lead to successful tissue retention. Given the increase in clinical applications with SVF (ADRCs), the authors believe that it is important to provide additional context regarding the proper and thorough preparation of this heterogenous cell population. Aronowitz et al have provided important insight into a variety of commercial and noncommercial methods of SVF preparation. ${ }^{44,45}$ These authors confirmed that the breakdown of the extracellular matrix of adipose that is achieved via proteolytic enzymes (the method used in this case series) produces a significantly greater efficiency compared to SVF isolated through mechanical methods. Furthermore, these authors note that SVF produced by nonenzymatic methods are less pure, containing a higher frequency of blood mononuclear cells and few progenitor cells.

Currently, there are few, if any, minimally invasive, autologous cell therapeutic modalities being developed that address early alopecia. However, analyses from other therapeutic applications of ADRCs and AFT suggest that a cell-enrichedbased approach for the treatment of early alopecia may be of significant benefit. In this pilot case series, the safety and tolerability of using autologous fat grafting enriched with ADRC in a series of patients with androgenic alopecia are reported. In this first of a kind study, the authors demonstrate that the procedure is safe and tolerable when applied as a treatment for MHPL and FHPL. The results demonstrate an encouraging response that seems to be consistent with other previously published approaches using conditioned media. The limitations of the study include open-label, nonblinded analysis, and small sample size. Despite these limitations, this initial data experience demonstrates that scalp stem cell-enriched fat grafting may represent a promising alternative approach for treating baldness in men and women. Based on these findings, the authors advocate that further research is needed and is ongoing.

\section{Disclosure}

Dr Daniels is an officer and shareholder of Kerastem Technologies, LLC. Drs Perez-Meza, Ziering, Sforza, Krishnan, and Ball report no conflicts of interest in this work.

\section{References}

1. Hamilton JB. Patterned loss of hair in man: types and incidence. Ann NY Acad Sci. 1951;53:708-728.

2. Norwood O. Male pattern baldness: classification and incidence. South Med J. 1975;68:1359-1365.
3. Rhodes T, Girman CJ, Savin RC, et al. Prevalence of male pattern hair loss in 18-49 year old men. Dermatol Surg. 1998;24:1330-1332.

4. Otberg N, Finner AM, Shapiro J. Androgenetic alopecia. Endocrinol Metab Clin North Am. 2007;36(2):379-398.

5. Stough D, Stenn K, Haber R, et al. Psychological effect, pathophysiology, and management of androgenetic alopecia in men. May Clin Proc. 2005;80(10):1316-1322.

6. Krupa Shankar DS, Chakravarthi M, Shilpakar R. Male androgenetic alopecia: population base study in 1,005 subjects. Int $J$ Tricology. 2009;1(2):131-133.

7. Gan DCC, Sinclair RD. Prevalence of male and female pattern hair loss in Maryborough. J Investig Dermatol Symp Proc. 2005;10:184-189.

8. Cash TF, Price VH, Savin RC. Psychological effects of androgentic alopecia on women: comparisons with balding men and with female control subjects. J Am Acad Dermatol. 1993;29(4):568-575.

9. Leavitt ML. Women and Hair Loss. Atlanta, USA: Beautiful Media Publisher; 2004.

10. Dinh QQ, Sinclair R. Female pattern hair loss: current treatment concepts. Clin Interv Aging. 2007;2(2):189-199.

11. Ghanaat M. Types of hair loss and treatment options, including the novel low-level light therapy and its proposed mechanism. South Med J. 2010;103(9):917-921.

12. Shapiro J, Kaufman KD. Use of finasteride in the treatment of men with androgenetic alopecia (male pattern hair loss). J Investig Dermatol Symp Proc. 2003;8(1):20-23.

13. Ross EK, Shapiro J. Management of hair loss. Dermatol Clin. 2005; 23(2):227-243.

14. Leavitt M, Perez-Meza D, Rao N, Barusco M, Kaufman KD, Ziering C. Effects of finasteride $1 \mathrm{mg}$ on hair transplantation. Dermatol Surg. 2005;31(10);1268-1276.

15. Leavitt M, Perez-Meza D, DiBernardo B. Low level laser therapy in hair loss. Laser and non-surgical rejuvenation. Tech Aesthet Plas Surg. 2009;141-153.

16. Ziering C. Experience with robotic surgery in hair transplantation. In: Programs and abstracts. XX Orlando Live Surgery Workshop; Orlando, FL, USA: April, 2014.

17. Perez-Meza D. The Use of SVF and PRP for the treatment of Scarring and non-Scarring Alopecias. In: Programs and abstracts. 1st Meeting of the SILATC; Las Vegas, NV, USA: September 27, 2016.

18. Perez-Meza D, Niedbalski R. Complications in hair restoration surgery. Oral Maxillofac Surg Clin North Am. 2009;21(1):119-148.

19. Perez-Meza D. Complications preoperative, intraoperative and postoperative following hair transplantation. In: Programs and abstracts. XX Orlando Live Surgery Workshop; Orlando, FL, USA: April, 2014.

20. Perez-Meza D. Complicaciones en transplante del pelo. In: Programs and abstracts. Ier congreso de la SILATC; 2016; Las Vegas, Nevada.

21. Voguel JE. Correction of the cornrow hair transplant and other common problems in surgical hair restoration. Plastic Reconstr Surg. 2000; 105(4):1528-1536.

22. Mysore V. Finasteride and sexual side effects. Indian Dermatol Online J. 2012;3(1):62-65.

23. Magerl M, Paus R, Farjo N, Muller-Rover S, Peters EM, Foitzik K, Tobin DJ. Limitations of human occiptal scalp hair follicle organ culture for studying the effects of minoxidil as a hair growth enhancer. Exp Dertmatol. 2004;13(10):535-542.

24. Zuk PA, Zhu M, Ashjian P, et al. Human adipose tissue is a source of multipotent stem cells. Mol Biol Cell. 2002;13:4279-4295.

25. Festa E, Fretz J, Berry R, et al. Adipocyte lineage cells contribute to the skin stem cell niche to drive hair cycling. Cell. 2011;146:761-771.

26. Shin H, Ryu Ho H, Kwon O, Byung-Soon P, Jo Jin S. Clinical use of conditioned media of adipose tissue-derived stem cells in female pattern hair loss: a retrospective case series study. Int J Dermatol. 2015;54(6):730-735.

27. Zhu M, Zhou Z, Chen Y, et al. Supplementation of fat grafts with adipose-derived regenerative cells improves long-term graft retention. Ann Plast Surg. 2010;64:222-228.

28. Coleman SR. Structural fat grafts: the ideal filler? Clin Plast Surg. 2001;28:111-119. 
29. Dini M, Mori A, Quattrini Li A. Eyebrow regrowth in patient with atrophic scarring alopecia treated with an autologous fat graft. Dermatol Surg. 2014;40(8):926-928.

30. Festa E, Fretz J, Berry R, et al. Adipocyte lineage cells contribute to the skin stem cell niche to drive hair cycling. Cell. 2011;146:761-771.

31. Schmidt B, Horsley V. Unraveling hair follicle-adipocyte communication. Exp Dermatol. 2012;21:827-830.

32. Coleman SR. Structural fat grafts: the ideal filler? Clin Plast Surg. 2001; 28:111-119.

33. Locke MB, de Chalain TM. Current practice in autologous fat transplantation: suggested clinical guidelines based on a review of recent literature. Ann Plast Surg. 2008;60:98-102.

34. Missana MC, Laurent I, Barreau L, Balleyguier C. Autologous fat transfer in reconstructive breast surgery: indications, technique and results. Eur J Surg Oncol. 2007;33:685-690.

35. Zocchi ML, Zuliani F. Bicompartmental breast lipostructuring. Aesthetic Plast Surg. 2008;32:313-328.

36. Yoshimura K, Sato K, Aoi N, Kurita M, Hirohi T, Harii K. Cellassisted lipotransfer for cosmetic breast augmentation: supportive use of adipose-derived stem/stromal cells. Aesthetic Plast Surg. 2008;32: 48-55.

37. Illouz YG, Sterodimas A. Autologous fat transplantation to the breast: a personal technique with 25 years of experience. Aesthetic Plast Surg. 2009;33(5):706-715.
38. Yi CG, Xia W, Zhang LX, et al. VEGF gene therapy for the survival of transplanted fat tissue in nude mice. J Plast Reconstr Aesthet Surg. 2007;60:272-278.

39. Yamaguchi M, Matsumoto F, Bujo H, et al. Revascularization determines volume retention and gene expression by fat grafts in mice. Exp Biol Med (Maywood). 2005;230:742-748.

40. Akita S, Akino K, Hirano A, Ohtsuru A, Yamashita S. Mesenchymal stem cell therapy for cutaneous radiation syndrome. Health Physics. 2010;98(6):858-862.

41. Alvarez PD, Garcia-Arranz M, Georgiev-Hristov T, Garcia-Olmo D. A new bronchoscopic treatment of tracheomediastinal fistula using autologous adipose-derived stem cells. Thorax. 2008;63:374-376.

42. Zhu M, Zhou Z, Chen Y, et al. Supplementation of fat grafts with adipose-derived regenerative cells improves long-term graft retention. Ann Plast Surg. 2010;64:222-228.

43. Matsumoto D, Sato K, Gonda K, et al. Cell-assisted lipotransfer: supportive use of human adipose-derived cells for soft tissue augmentation with lipoinjection. Tissue Eng. 2006;12:3375-3382.

44. Aronowitz JA, Lockhart RA, Hakakian CS. Mechanical versus enzymatic isolation of stromal vascular fraction cells from adipose tissue. Springerplus. 2015;4:713.

45. Aronowitz JA, Lockart RA, Hakaian CS, Birnbaum ZE. Adipose stromal vascular fraction isolation: a head-to-head comparison of 4 cell separation systems \#2. Ann Plast Surg. 2016;77(3):354-362.
Stem Cells and Cloning: Advances and Applications

\section{Publish your work in this journal}

Stem Cells and Cloning: Advances and Applications is an international, peer-reviewed, open access journal. Areas of interest in stem cell research include: Embryonic cell stems; Adult stem cells; Blastocysts; Cordblood stem cells; Stem cell transformation and culture; Therapeutic cloning; Umbilical cord blood and bone marrow cells; Laboratory,

\section{Dovepress}

animal and human therapeutic studies; Philosophical and ethical issues related to stem cell research. This journal is indexed on CAS. The manuscript management system is completely online and includes a quick and fair peer-review system. Visit http://www.dovepress.com/ testimonials.php to read real quotes from published authors.. 